\title{
DETECTION OF MYCOBACTERIUM TUBERCULOSIS COMPLEX IN CLINICALLY SUSPECTED CASES OF TUBERCULOSIS BY AUTOMATED CULTURE METHOD AND NESTED POLYMERASE CHAIN REACTION
}

\author{
Ritu Kansal1, Vandana Sardana², Anita Pandey³ \\ ${ }_{1}^{1}$ Assistant Professor, Department of Microbiology, MRA Medical College, Akbarpur, Ambedkar Nagar, Uttar Pradesh, India. \\ ${ }^{2}$ Associate Professor, Department of Microbiology, Subharti Medical College. Meerut, Uttar Pradesh, India. \\ 3 Professor and HOD, Department of Microbiology, Subharti Medical College. Meerut, Uttar Pradesh. India.
}

\begin{tabular}{l}
\hline ABSTRACT \\
BACKGROUND \\
In India, one of the major health problems that has a high mortality rate is Tuberculosis. Thus, rapid detection is a great necessity in \\
today's scenario to combat the threat. We wanted to assess the diagnostic utility of liquid broth based automated culture technique \\
in comparison with molecular technique i.e. PCR for diagnosis of suspected cases of pulmonary tuberculosis.
\end{tabular}

\section{METHODS}

It is a cross-sectional study in which 370 specimens collected from different wards and OPDs at C.S.S.H, Subharti Medical College were processed for Mycobacterium tuberculosis by three methods: Ziehl-Neelsen staining, automated liquid culture and by PCR amplification in which insertion element IS6110 with $123 \mathrm{bp}$ fragment of $M$. tuberculosis complex were targeted by primers. Liquid culture method was taken as the ideal method.

\section{RESULTS}

Out of the 370 samples, acid fast bacilli were seen in 52 samples by ZN staining, by BacT/ALERT 3D culture, 89 were positive for mycobacteria and 119 samples were positive by PCR. Significant statistical difference was observed between PCR and Smear microscopy $(\mathrm{p}<0.05)$.

\section{CONCLUSIONS}

This study shows the usefulness of IS6110-based polymerase chain reaction in detecting tuberculosis cases in tertiary care hospitals in Western Uttar Pradesh which were negative by other tests. Thus, PCR is a rapid and highly sensitive test.

HOW TO CITE THIS ARTICLE: Kansal R, Sardana V, Pandey A. Detection of Mycobacterium tuberculosis complex in clinically suspected cases of tuberculosis by automated culture method and nested polymerase chain reaction. J. Evolution Med. Dent. Sci. 2019;8(18):1439-1442, DOI: 10.14260/jemds/2019/320

\section{BACKGROUND}

Tuberculosis (TB), a major public health problem which has a high death rate. India stands second populous country in the world and one fourth of the global incident TB cases occur in India annually. According to WHO Global TB Report, 2015, out of the estimated global annual incidence of 9.6 million TB cases, 2.2 million were estimated to have occurred in India. ${ }^{1}$ In developing countries extrapulmonary tuberculosis (EPTB) is in increasing trend. The diagnosis of EPTB is very challenging because of its different clinical presentations. ${ }^{2,3}$ To diagnose early has a major part in controlling TB. Although smear microscopy, and Lowenstein Jensen (LJ) culture are the conventional tests for the diagnosis of TB, but these techniques have low sensitivity and slow growth, especially with clinical samples that contain very few microorganisms as in cases of EPTB. $4,5,6$

'Financial or Other Competing Interest': None.

Submission 28-01-2019, Peer Review 18-04-2019,

Acceptance 24-04-2019, Published 06-05-2019.

Corresponding Author:

Dr. Vandana Sardana

Associate Professor

Department of Microbiology,

Subharti Medical College,

Meerut-250005

Utter Pradesh, India.

E-mail: ritukansal_2006@yahoo.co.in.

DOI: $10.14260 /$ jemds $/ 2019 / 320$

\section{(c) $(1) \odot$}

Therefore, great difficulty will be encountered in initiating early therapy especially seen in cases of EPTB if there is lack of sensitive, specific and rapid method. ${ }^{7}$ Proper treatment needs the early detection of M. tuberculosis. Molecular techniques has the advantage of giving highly sensitive and specific results within few hours. At present, nucleic acid amplification (NAA) techniques like polymerase chain reaction (PCR) has completely changed the scenario of detecting infectious pathogens such as M. tuberculosis within few hours. Mobile genetic element i.e. insertion sequence IS6110 is specific for the Mycobacterium tuberculosis complex.8 IS6110-based PCR amplification with primers targeting $123 \mathrm{bp}$ fragment of insertion sequence is most common method. The aim of this study was to compare the efficacy of PCR test with conventional Ziehl-Neelsen (ZN) staining and automated BacT/ALERT 3D system in clinical samples of patients attending the tertiary care hospital.

\section{METHODS}

\section{Clinical Specimens and Data Collection}

In this cross-sectional study, 370 clinical samples of patients attending the OPD and IPD wards at tertiary care hospital between February 2013 and March 2017 were processed. Clinical samples included 119 pleural fluid, 76 cerebrospinal fluid (CSF), 48 blood samples, 34 ascitic fluid, 25 sputum samples, 23 endometrial tissue, 21 pus, 10 urine, 6 BAL, 3 synovial fluid, 2 granulomatous tissue, 2 bone piece, and 1 bone marrow from patients suspected of tuberculosis visiting inpatient and outpatient department of Chhatrapati Shivaji 
Subharti hospital, Meerut. Samples were received in sterile containers in clinical microbiology laboratory and were processed for direct microscopy by Z-N staining, Bact/ALERT 3D \& nested PCR. Each sample was subjected to homogenization, decontamination and concentration.

Smear Examination, Culture of M. tuberculosis Complex The samples were transported without any delay to the laboratory. All samples were seen for the bacilli by Z-N staining. ${ }^{9}$ all non-sterile samples were treated for digestion, decontamination and concentration by $\mathrm{N}$-acetyl-L-cysteineSodium hydroxide (NALC-NaOH) method.10 The decontaminated samples were processed both for the Z-N staining for examination of acid fast bacilli. ${ }^{11}$ and culture on BacT/ALERT 3D. $0.5 \mathrm{ml}$ of the processed specimen, was inoculated into BacT/ALERT 3D process bottle, which contains $10 \mathrm{ml}$ of Modified Middlebrook 7H9 broth supplemented with bovine serum albumin, catalase and casein. As per the manufacturers' instructions, $\mathrm{MB} /$ BacT antibiotic supplement (amphotericin B, azlocillin, nalidixic acid, polymyxin B, trimethoprim, vancomycin) in $0.5 \mathrm{ml}$ of reconstitution fluid (amaranth, glycerol, Tween-80, purified water) was added to the process bottle before the inoculation of the processed sample. The MB/BacT process bottle was incubated at $37^{\circ} \mathrm{C}$ till it was designated positive or up to a maximum of 4-6 weeks.

\section{DNA Extraction}

DNA extraction was done from different clinical samples by different methods, as per mentioned protocol (Bangalore Genei, Bangalore, India).

\section{Oligonucleotide Primers}

IS6110, a widely used primer, is 1191-bp repetitive insertion sequence that is usually present $6-20$ times in the $M$. tuberculosis complex genome. 12

\section{DNA Amplification by Polymerase Chain Reaction}

The amplification was done in thermal cycler (Lab India Life Science). The principle is based on nested PCR method, which is a powerful and sensitive diagnostic tool. This assay is a twostep sequential assay. In the first step, the IS region of $M$. tuberculosis complex DNA sequence, a $220 \mathrm{bp}$ is amplified by specific external primers. In the second step, the nested primers are added to further amplify a $123 \mathrm{bp}$ amplification product. The separation of the amplified product was done on 2.5\% agarose gel (Electrophoresis unit by Lab India) \& visualized on a Gel documentation system (Bangalore Genei, Bangalore, India). The presence of $123 \mathrm{bp}$ fragment indicates the positive test for $M$. tuberculosis complex. The Positive control included were DNA of H37Rv strain (PC1) and kit internal Positive control (PC 2) and Negative control included kit internal negative control (NC 1)and molecular grade water (NC 2) [Figure 1].

\section{Statistical Analysis}

Sensitivity, specificity, positive predictive value and negative predictive value of the tests employed were analysed using Stata 14.0 statistical software.

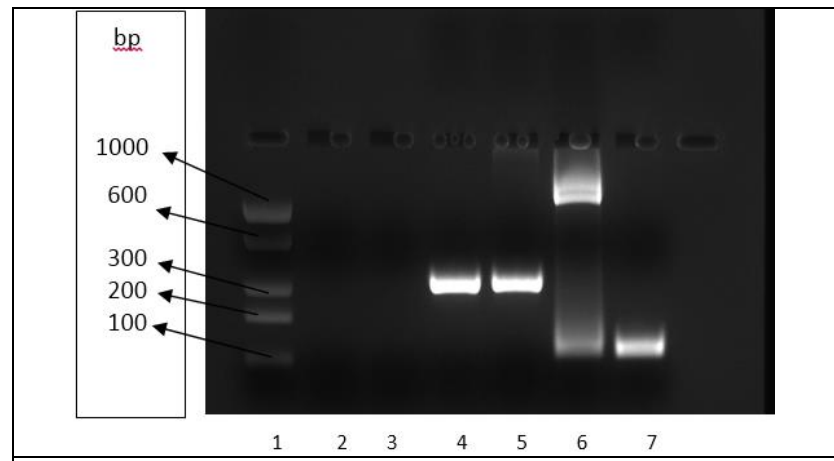

Figure 1. PCR-Based Detection of M. tuberculosis Complex Targeting IS6110

Lane 1: Molecular weight marker, Lane 2: Kit Internal negative control (NC 1), Lane 3: Molecular grade water (NC 2), Lane 4: Negative sample, Lane 5: Negative sample, Lane 6: H37Rv (PC 1), Lane 7: Kit internal Positive Control (PC 2)

\begin{tabular}{|c|c|c|c|}
\hline \multirow{2}{*}{ Tests Performed } & \multicolumn{2}{|c|}{ Results } & \multirow{2}{*}{$\begin{array}{c}\text { Detection } \\
\text { Rate }\end{array}$} \\
\cline { 2 - 3 } & Negative & Positive & $14.1 \%$ \\
\hline Zn smear & 318 & 52 & $24.1 \%$ \\
\hline BacT/Alert culture & 281 & 89 & $24 \%$ \\
\hline PCR & 251 & 119 & $32.2 \%$ \\
\hline
\end{tabular}

Table 1. Comparison of Results in Three Different Tests. $(n=370)$

\begin{tabular}{|c|c|c|c|c|}
\hline \multirow{2}{*}{$\begin{array}{l}\text { Nature of } \\
\text { Clinical } \\
\text { Samples }\end{array}$} & \multirow{2}{*}{$\begin{array}{c}\text { Total } \\
\text { Samples }\end{array}$} & \multicolumn{3}{|c|}{$\begin{array}{c}\text { Detection Rate in Number (\%) } \\
\text { by Different Tests }\end{array}$} \\
\hline & & $\mathrm{ZN}$ & $\begin{array}{l}\text { BacT/ } \\
\text { ALERT }\end{array}$ & PCR \\
\hline $\begin{array}{c}\text { Pulmonary } \\
\text { (Sputum, BAL) }\end{array}$ & 31 & $\begin{array}{c}11 \\
(35.5 \%) \\
\end{array}$ & $\begin{array}{c}17 \\
(54.8 \%) \\
\end{array}$ & $\begin{array}{c}20 \\
(64.5 \%) \\
\end{array}$ \\
\hline $\begin{array}{l}\text { Extrapulmonary } \\
\text { (Pleural fluid, } \\
\text { ascitic fluid, } \\
\text { synovial fluid, } \\
\text { endometrial } \\
\text { tissue, pus, CSF } \\
\text { and others) } \\
\end{array}$ & 339 & $\begin{array}{c}41 \\
(12.1 \%)\end{array}$ & $\begin{array}{c}72 \\
(21.2 \%)\end{array}$ & $\begin{array}{c}99 \\
(29.2 \%)\end{array}$ \\
\hline Total & 370 & 52 & 89 & 119 \\
\hline
\end{tabular}

\begin{tabular}{|c|c|c|}
\hline \multirow{2}{*}{\begin{tabular}{c} 
Test $\begin{array}{c}\text { Result Category } \\
\text { (No.) }\end{array}$ \\
\cline { 2 - 3 } Pmear positive(52)
\end{tabular}} & Positive & Negative \\
\hline Smear negative (318) & 52 & 0 \\
\hline BacT/ALERT positive (89) & 87 & 251 \\
\hline $\begin{array}{c}\text { BacT/ALERT negative } \\
(281)\end{array}$ & 30 & 0 \\
\hline $\begin{array}{c}\text { Table 3. Comparison of PCR Results with Other Modalities } \\
\text { (n=370) }\end{array}$ \\
\hline
\end{tabular}

\begin{tabular}{|c|c|c|c|c|}
\hline \multirow{2}{*}{ Smear } & \multicolumn{2}{|c|}{ PCR Positive } & \multicolumn{2}{c|}{ PCR Negative } \\
\cline { 2 - 5 } & Culture + & Culture - & Culture + & Culture - \\
\hline $\begin{array}{c}\text { Smear Positive } \\
(\mathrm{n}=52)\end{array}$ & 50 & 2 & 00 & 00 \\
\hline $\begin{array}{c}\text { Smear } \\
\text { Negative } \\
(\mathrm{n}=318)\end{array}$ & 39 & 28 & 00 & 251 \\
\hline Table 4. Correlation of the Smear Result with PCR and \\
Culture \\
\hline
\end{tabular}




\begin{tabular}{|c|c|c|}
\hline Sensitivity & $100.00 \%$ & $95.94 \%$ to $100.00 \%$ \\
\hline Specificity & $89.32 \%$ & $85.11 \%$ to $92.68 \%$ \\
\hline Positive Likelihood Ratio & 9.37 & 6.68 to 13.14 \\
\hline Negative Likelihood Ratio & 0.00 & \\
\hline Disease prevalence & $24.05 \%\left(^{*}\right)$ & $19.79 \%$ to $28.74 \%$ \\
\hline Positive Predictive Value & $74.79 \%\left(^{*}\right)$ & $67.90 \%$ to $80.62 \%$ \\
\hline Negative Predictive Value & $\left.100.00 \%{ }^{*}\right)$ \\
\hline Table 5. Statistical Analysis of Correlation of PCR Culture \\
vs Culture \\
\hline
\end{tabular}

\begin{tabular}{|c|c|c|}
\hline Sensitivity & $56.18 \%$ & $45.25 \%$ to $66.68 \%$ \\
\hline Specificity & $99.29 \%$ & $97.45 \%$ to $99.91 \%$ \\
\hline Positive Likelihood Ratio & 78.93 & 19.60 to 317.89 \\
\hline Negative Likelihood Ratio & 0.44 & 0.35 to 0.56 \\
\hline Disease prevalence & $24.05 \%\left(^{*}\right)$ & $19.79 \%$ to $28.74 \%$ \\
\hline Positive Predictive Value & $96.15 \%\left(^{*}\right)$ & $86.13 \%$ to $99.02 \%$ \\
\hline Negative Predictive Value & $87.74 \%\left(^{*}\right)$ & $84.97 \%$ to $90.05 \%$ \\
\hline Table 6. Statistical Analysis of Correlation of ZN vs Culture \\
\hline
\end{tabular}

\section{RESULTS}

A total of 370 specimens from tuberculosis suspected patients were evaluated for the presence of $M$. tuberculosis infection by conventional ZN staining, automated culture and molecular technique. Results of 370 samples were compared accordingly [Table-1, 2]. ZN smear was positive in $14.1 \%$ of suspected cases. BacT/ALERT 3D culture showed growth in $24.1 \%$ of suspected cases of tuberculosis. In comparison with above two modalities, PCR gave significantly higher (i.e. $32.2 \%$ ) positive cases. [Table 3, 4]. The patients included 184 males and 186 females. In 50 cases, all the three tests were positive. The sensitivity of Smear examination and PCR was compared vis a vis with BacT/ALERT culture result (Table 5, 6). The analysis of the results of PCR and the conventional tests were done by using Stata v 14.0 statistical software.

\section{DISCUSSION}

ZN staining is commonly used in India primarily because of its cheap, easily availability criteria, even though it is not so sensitive. ${ }^{13}$ In the current study, positivity rate was found to be $14.1 \%$ of samples by ZN staining. Culture is the most commonly used method but lacks sensitivity, specificity and speed, especially in the detection of EPTB ${ }^{13}$. In this study, only $24.1 \%$ of the clinical samples showed growth on BacT/ALERT. This is higher than smear positivity (14.1\%) but lower than PCR positivity (32.2\%).

Whenever PCR was performed in a right time, PCR was found to to be a very highly sensitive test in EPTB. 14,15,16 In the current study, PCR could detect $M$. tuberculosis in $32.2 \%$ of the tested cases. Among all the cases processed by different methods, PCR detected the maximum number (119) of cases. All the culture positive samples were also positive by PCR.

There were two cases positive by smear and PCR but were culture negative. This could be due of the presence of dead mycobacteria in the samples as some of the subjects were on anti-tubercular treatment. PCR test can detect very low number and even nonviable bacteria in a sample which can be present in a symptomatic individual. ${ }^{17}$ This may be the reason for 30 culture negative samples, which turned out to be PCR positive. PCR test was found to be more sensitive (29.2\%) than smear $(12.1 \%)$ and culture $(21.2 \%)$ in diagnosis of extra pulmonary TB. PCR test detected M. tuberculosis within few hours, as compared to around 3-4 weeks required for detection by BacT/ ALERT techniques. ${ }^{18}$ The high specificity, sensitivity and speed of PCR test in diagnosis of M. tuberculosis infection is observed in this study that encourages the utility of this method in routine diagnosis of TB especially where prevalence of tuberculosis is extremely high and also in case of extra pulmonary tuberculosis where it is very difficult to diagnose with other method. The slow method of diagnosis leads to treatment delay which further transmits bacilli to more susceptible patients. Conventional staining techniques cannot diagnose mainly EPTB cases because of many problems like the pauci-bacillary nature of the samples, inadequate sample amount or volume; uneven distribution of microorganism in various samples etc. This has proved the profitability of polymerase chain reaction particularly in the laboratory diagnosis of EPTB. ${ }^{19}$ Thus IS6110 sequence for the M. tuberculosis complex (M. tuberculosis, M. africanum, $M$. bovis, M. microti and M. canetti) is an ideal target for amplification. ${ }^{20,21}$

Similarly, Maurya et al., 2012; Sekar et al., 2008; Garcia et al., 2009; Negi et al., 2006; Tiwari et al., 2003; Gomez et al., 2000 and Sankar et al., 2010 in their study also found more positive cases by PCR targeting the IS6110 element in specimens of EPTB.2,16,19,22,23,24,25

The results of PCR in this study clearly show that PCR technique being highly specific and sensitive method should be used in a priority basis for the benefit of the patient.

\section{CONCLUSIONS}

The rapidity and high sensitivity of PCR targeting IS6110 gene sequence, compared to smear and culture, compensates for the higher cost of the test in the diagnosis of cases. It showed its advantage not only for diagnosis in smear negative 67 (56.3\%) cases, but also in culture negative 30 (25.2\%) cases. Molecular diagnosis should be performed when there is strong clinical suspicion and negative conventional techniques. Early treatment to patients helps in preventing further dissemination of M. tuberculosis in the environment.

\section{Acknowledgement}

We are thankful to our Principal Dr. A. K. Asthana for giving us the permission to conduct this study.

\section{REFERENCES}

[1] Revised National Tuberculosis Control Programme. TB India 2016. RNTCP Annual Status Report. Central TB Division Directorate General of Health and Family Welfare, Nirman Bhawan, New Delhi, 2016.

[2] Maurya AK, Kant S, Nag VL, et al. Detection of 123 bp fragment of insertion element IS6110 Mycobacterium tuberculosis for diagnosis of extrapulmonary tuberculosis. Indian J Med Microbiol 2012;30(2): 182-6.

[3] Cailhol J, Decludt B, Che D. Sociodemographic factors that contribute to the development of extrapulmonary tuberculosis was identified. J Clin Epidemiol 2005;58(10):1066-71. 
[4] Jonas V, Alden MJ, Curry JI, et al. Detection and identification of Mycobacterium tuberculosis directly from sputum sediments by amplification of rRNA. J Clin Microbiol 1993;31(9):2410-6.

[5] Mathai A, Radhakrishnan W, George SM, et al. A newer approach for the laboratory diagnosis of tuberculous meningitis. Diagn Microbiol Infect Dis 2001;39(4):2258.

[6] Grange JM. The rapid diagnosis of paucibacillary tuberculosis. Tubercle 1989;70(1):1-4.

[7] Ong A, Creasman J, Hopewell PC, et al. A molecular epidemiological assessment of extrapulmonary tuberculosis in San Franciso. Clin Infect Dis 2004;38(1):25-31.

[8] Thierry D, Cave MD, Eisenach KD, et al. IS6110, an ISlike element of Mycobacterium tuberculosis complex. Nucleic Acids Res 1990;18(1):188.

[9] Revised National Tuberculosis Control Programme. Laboratory Manual for Sputum Smear Microscopy. New Delhi: Central TB Division, Directorate General of Health Services, Ministry of Health and Family Welfare, 2005.

[10] Kent PT, Kubica GP. Public Health mycobacteriology: a guide for the level III laboratory. Atlanta, GA USA: Centres for Disease Control, 1985: p. 207.

[11] Baron EJ, Finagold SM. Mycobacteria. In: Bailey and Scott's Diagnostic Microbiology. 9th edn. Louis: The CV Mosby Company 1994: p. 590-633.

[12] Eisenach KD, Cave MD, Bates JH, et al. Polymerase chain reaction amplification of a repetitive DNA sequence specific for Mycobacterium tuberculosis. J Infect Dis 1990;161(5):977-81.

[13] Torrea G, Van de Perre P, Ouedraogo M, et al. PCR-based detection of the Mycobacterium tuberculosis complex in urine of HIV-infected and uninfected pulmonary and extrapulmonary tuberculosis patients in Burkina Faso. J Med Microbiol 2005;54(Pt 1):39-44.

[14] Pai M, Minion J, Steingart K, et al. New and improved tuberculosis diagnostics: evidence, policy, practice and impact. Current Opinion in Pulmonary Medicine 2010;16(3):271-84

[15] Vadwai V, Boehme C, Nabeta P, et al. Xpert MTB/RIF: a new pillar in diagnosis of extrapulmonary tuberculosis? J Clin Microbiol 2011;49(7):2540-5.
[16] Sekar B, Selvaraj L, Alexis A, et al. The utility of IS6110 sequence based polymerase chain reaction in comparison to conventional methods in the diagnosis of extra-pulmonary tuberculosis. Indian J Med Microbiol 2008;26(4):352-5.

[17] Afghani B, Lieberman JM, Duke MB, et al. Comparison of quantitative polymerase chain reaction, acid fast bacilli smear and culture results in patients receiving therapy for pulmonary tuberculosis. Diag Microb Infect Dis 1997;29(2):73-9.

[18] D'Amato RF, Hochstein LH, Colaninno PM, et al. Application of the Roche Amplicor Mycobacterium tuberculosis (PCR) test to specimens other than respiratory secretions. Diag Microbiol Infect Dis 1996;24(1):15-7.

[19] Garcia-Elorriaga G, Gracida-Osorno C, Carrillo-Montes $\mathrm{G}$, et al. Clinical usefulness of the nested polymerase chain reaction in the diagnosis of extrapulmonary tuberculosis. Salud Publica Mex 2009;51(3):240-5.

[20] Perkins MD. New diagnostic tools for tuberculosis. Int J Tuberc Lung Dis 2004;4(12 Suppl 2):S182-S8.

[21] Ehlers S, Ignatius R, Regnath $\mathrm{T}$, et al. Diagnosis of extrapulmonary tuberculosis by Gen-Probe amplified Mycobacterium tuberculosis direct test. J Clin Microbiol 1996;34(9):2275-9.

[22] Negi SS, Anand R, Basir SF, et al. Protein antigen b (Pab) based PCR test in diagnosis of pulmonary and extrapulmonary tuberculosis. Indian J Med Res 2006;124(1):81-8.

[23] Tiwari V, Jain A, Verma RK. Application of enzyme amplified mycobacterial DNA detection in the diagnosis of pulmonary and extra-pulmonary tuberculosis. Indian J Med Res 2003;118:224-8.

[24] Portillo-Gomez L, Morris SL, Panduro A. Rapid and efficient detection of extra-pulmonary Mycobacterium tuberculosis by PCR analysis. Int J Tuberc Lung Dis 2000;4(4):191-200.

[25] Sankar S, Balakrishnan B, Nandagopal B, et al. Comparative evaluation of Nested PCR and conventional smear methods for the detection of Mycobacterium tuberculosis in sputum samples. Molecular Diagnosis \& Therapy 2010;14(4):223-7. 